\title{
Evaluation of a district growth screening programme: the Oxford growth study
}

Department of Paediatrics, John Radcliffe Hospital, Oxford OX3 9DU

M L Ahmed

A D Allen

A Sharma

J A Macfarlane

D B Dunger

Correspondence and reprint requests to: Dr Dunger.

Accepted 25 May 1993

\author{
M L Ahmed, A D Allen, A Sharma, J A Macfarlane, D B Dunger
}

\begin{abstract}
The Oxford district growth screening programme was established in 1988 as a community based survey of the heights of children at 3 and 4.5 years of age in a district of 550000 people. The current birthrate is 7500 births/year and over the first three years of the study 20338 children were screened in the community; the ascertainment ranged from $61-73.9 \%$ of the total expected. Mean height SD scores were significantly greater than the British standards: mean SD scores for boys and girls were 0.33 and 0.35 respectively at age 3 , and 0.20 and 0.26 at 4.5 years. Altogether $260(1.3 \%)$ of the total cohort were found to have heights $\leqslant-2 S D$ scores. The mean growth velocity of 2742 children measured at 3 and 4.5 years of age was similar to that of the national standards, $7 \cdot 14 \mathrm{~cm} /$ year in boys and $7 \cdot 21$ $\mathrm{cm} /$ year in girls.

Follow up data was available from 149 children whose heights were confirmed to be $\leqslant-2$ SD scores. Of these 69 were already under the care of paediatricians. Thus far diagnoses in the 149 have included growth hormone deficiency $(n=2)$, Turner's syndrome $(n=2)$, Noonan's syndrome $(n=4)$, and emotional deprivation $(n=1)$. Ways in which ascertainment and detection of treatable causes of short stature could be improved are discussed and it is concluded that community growth screening is a useful part of the child health surveillance programme.
\end{abstract}

(Arch Dis Child 1993; 69: 361-365)

Growth screening has been used as a method of monitoring the general level of the health of a population, ${ }^{1-4}$ but it can also be used to help identify individual children who may have undiagnosed conditions that affect their growth. ${ }^{5}$ Recent national recommendations relating to child health surveillance recommend that all children should be screened for height at 3 and 4.5 years of age. ${ }^{6}$

Most previous height screening programmes in the UK have been established on a research basis using specialised personnel. ${ }^{57}$ The limitation of these studies is that they are expensive and without a firm population base. For screening to be established on a service basis it must be incorporated into the continuing child health surveillance programme. Growth screening wall charts were distributed throughout the Oxford district to child health clinics in 1982/3. These charts, devised by Aynsley-Green and Macfarlane, ${ }^{8}$ led to an increased awareness among primary health care workers of the problems of short stature and referrals from health visitors and general practitioners (GPs) increased over subsequent years. We have previously shown that measurements by health visitors are sufficiently accurate for height screening. ${ }^{9}$ The current study therefore attempts to establish a community based district screening programme using existing primary health care personnel, and we report the results in the first 20000 children screened.

\section{Subjects and methods}

STUDY DESIGN

All Oxfordshire children are called for development checks at 3 and 4.5 years of age by the primary health care team. The health visitors and GPs have been asked to measure children's heights as part of this assessment. Height measurements are recorded and returned by health visitors and GPs on specially prepared forms.

Information on height measurements is then recorded on a computer database using a specially designed programme based on $\mathrm{dBase}$ IV. This has been programmed using Tanner and Whitehouse data ${ }^{1011}$ and provides an immediate check on the height SD score on each child entered, and will show the growth velocity and growth velocity SD score when a child has been screened twice.

$$
\text { SD score }=\frac{x-\bar{x}}{S D}
$$

where $\mathbf{x}$ is the child's height, $\bar{x}$ is the mean height for that age and sex, and SD is the SD for that age and sex.

Any child whose height SD score is found to be -2.0 or more below the mean is highlighted by the programme. The family, health visitor, and GP are then contacted and arrangements made for the child to attend one of three community based growth assessment clinics (14 a year) which are staffed by an experienced auxologist (MLA). If a child's height SD score is -3.0 or more below the mean, then direct referral to the consultant (DBD) is recommended. Children who attend the community growth assessment clinic are seen at intervals of six months until height has been accurately measured over one year. On each occasion height is measured in the recommended way ${ }^{12}$

^Raven Equipment Ltd, Unit 4, Ford Farm Industrial Complex, Braintree Road, Dunmow, Essex CM6 1HU. 
Table 1 Number of children screened compared with number expected

\begin{tabular}{lll}
\hline $\begin{array}{l}\text { Study } \\
\text { period }\end{array}$ & $\begin{array}{l}\text { No predicted } \\
\text { from } \\
\text { birthrate }\end{array}$ & $\begin{array}{l}\text { No (\%) of } \\
\text { measurements } \\
\text { recorded }\end{array}$ \\
\hline 3 year olds & & \\
Sept 1988-Aug 1989 & 6787 & $4162(61 \cdot 3)$ \\
$\quad \begin{array}{l}\text { Sept 1989-Aug 1990 } \\
\text { Mar 1990-Aug 1990 }\end{array}$ & 6990 & $4887(69 \cdot 9)$ \\
4.5 year olds & 3495 & $2585(73.9)$ \\
$\quad$ Sept 1988-Aug 1989 & 6710 & $4037(61 \cdot 0)$ \\
Sept 1989-Aug 1990 & 6817 & $4429(65 \cdot 0)$ \\
\hline
\end{tabular}

using a Magnimetre (Raven Equipment ${ }^{\star}$ ). Weight is also measured using a standard beam balance. At the annual visit a radiograph of the left hand and wrist is obtained. Bone age assessment is carried out using the Tanner and Whitehouse RUS system. ${ }^{13}$ If the child's annual growth rate is on or above the 25 th velocity centile, then a 12 month follow up appointment in the growth assessment clinic is arranged. Where the annual growth rate is less than the 25th centile the child is referred to the consultant (DBD) with the permission of the GP.

EQUIPMENT

Each health visitor in the district has been given a Microtoise (since superseded by the Minimetre, Child Growth Foundation $†$ ) and is asked to use it to measure children on her caseload. Some use the Oxford growth screening wall charts (Castlemead Publications $\ddagger$ ). Many 3 year olds are measured in their homes when a tape measure has to be used. The Microtoise has been found to be the most accurate and reliable $^{9}$ and health visitors and GPs should now be using this device.

In the community based growth assessment clinic the auxologist uses a Magnimetre. This consists of a wall mounted vertical piece and a removable headboard that is attached by two adjustable magnets to the fixed board. The measurement is read off a scale on the vertical wall piece.

RELIABILITY

Results from our previous study indicate that measurements made by the auxologist were likely to be $\pm 2 \cdot 1 \mathrm{~mm}$ of the 'true' value $95 \%$ of the time ( \pm 1.96 Smeas). Where the child was measured by the health visitor as $100 \mathrm{~cm}$ there was a $95 \%$ probability that the true height lay between $99 \cdot 2$ and $101.8 \mathrm{~cm}$. This allows for the bias attached to the measurement method. ${ }^{9}$

\section{Results}

ASCERTAINMENT

The measurements from 20338 children seen between 1988 and October 1990 have been analysed. These represent 11603 measure-

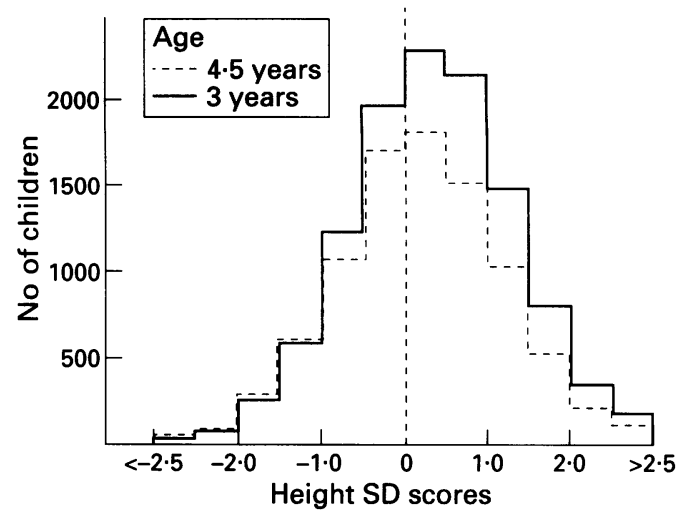

Figure 1 Height SD score distribution of 3 and 4.5 year olds.

ments of 3 year olds and 11477 measurements of 4.5 year olds. Of these 2742 children were measured at both ages.

Coverage over the two years of the study is shown in table 1 expressed as a percentage of the birth cohort. ${ }^{14}$ On average $93 \%$ of health visitors submitted returns. Of these returns $84 \%$ contained usable measurements. There were various reasons why measurements were not provided: (a) the child moved, (b) the child was transferred to another practice, (c) the child did not attend the child health clinic, (d) the child was too uncooperative to measure, (e) the parent refused, and (f) the measurement was not recorded. Delay in data entry and late returns by health visitors was also a problem especially with the 4.5 year old children.

\section{COMPARISON WITH BRITISH STANDARDS}

The distribution of height SD scores is illustrated in fig 1 . There is a shift to the right when compared with the standards of Tanner and Whitehouse. ${ }^{1011}$ The values are given in table 2 . In those children (2742) who had been screened at both 3 and 4.5 years mean velocity

Table 2 Height and height SD scores; values are mean (SD)

\begin{tabular}{lcc}
\hline & Boys & Girls \\
\hline 3 year olds & $(n=5968)$ & $(n=5635)$ \\
Age (years) & $3.085(0 \cdot 132)$ & $3.085(0 \cdot 136)$ \\
Height $(\mathrm{cm})$ & $96 \cdot 1(4 \cdot 0)$ & $95.0(4 \cdot 0)$ \\
Height SD score & $0.33(1 \cdot 00)$ & $0.35(1 \cdot 01)$ \\
4.5 year olds & $(n=5840)$ & $(n=5637)$ \\
Age (years) & $4 \cdot 622(0.200)$ & $4 \cdot 622(0 \cdot 196)$ \\
Height $(\mathrm{cm})$ & $106.7(4 \cdot 6)$ & $105 \cdot 8(4 \cdot 6)$ \\
Height SD score & $0.20(0 \cdot 99)$ & $0.26(0.99)$ \\
\hline
\end{tabular}

Table 3 Height and height velocity of those children seen at both 3 and 4.5 years; values are mean (SD)

\begin{tabular}{|c|c|c|}
\hline & $\begin{array}{l}\text { Boys } \\
(n=1394)\end{array}$ & $\begin{array}{l}\text { Girls } \\
(n=1348)\end{array}$ \\
\hline $\begin{array}{l}3 \text { year olds } \\
\text { Age (years) } \\
\text { Height (cm) } \\
\text { Height SD score }\end{array}$ & $\begin{array}{c}3.094(0 \cdot 14) \\
96 \cdot 0(4 \cdot 1) \\
0.29(1 \cdot 02)\end{array}$ & $\begin{array}{c}3 \cdot 101(0 \cdot 155) \\
94 \cdot 9(4 \cdot 1) \\
0 \cdot 28(1 \cdot 03)\end{array}$ \\
\hline $\begin{array}{l}4.5 \text { year olds } \\
\text { Age (years) } \\
\text { Height }(\mathrm{cm}) \\
\text { Height SD score }\end{array}$ & $\begin{array}{c}4 \cdot 582(0 \cdot 131) \\
106 \cdot 7(4 \cdot 5) \\
0 \cdot 24(0 \cdot 99)\end{array}$ & $\begin{array}{c}4 \cdot 586(0 \cdot 132) \\
105 \cdot 6(4 \cdot 6) \\
0 \cdot 26(0 \cdot 99)\end{array}$ \\
\hline $\begin{array}{l}\text { Velocity } \\
\text { Velocity SD score }\end{array}$ & $\begin{array}{l}7 \cdot 14(1 \cdot 63) \\
0.02(1 \cdot 34)\end{array}$ & $\begin{array}{l}7 \cdot 21(1.66) \\
0.07(1.41)\end{array}$ \\
\hline
\end{tabular}




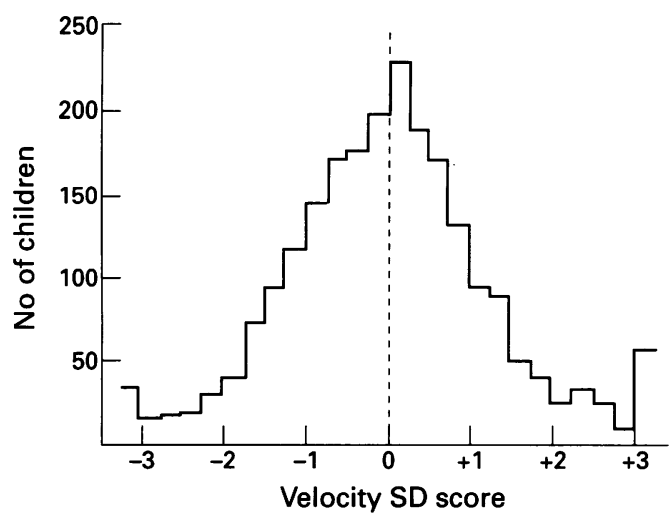

Figure 2 Height velocity SD score distribution.

was similar to the national standards. The distribution is shown in fig 2 , values are given in table 3 . Of these 2742 children measured at 3 and 4.5 years, 26 had heights $\leqslant-2$ SD scores at 3 years but not at 4.5 years. Only 12 children had heights $\leqslant-2$ SD scores at $4 \cdot 5$ years but not at 3 years.

ANALYSIS OF CHILDREN $\leqslant-2$ SD SCORES

Altogether $260(1.3 \%)$ of the children recorded as having height $\leqslant-2 S D$ scores were asked to attend follow up. Of these $76(29 \cdot 2 \%)$ were lost to follow up for the following reasons: refusal $(n=33)$, moved away $(n=11)$, did not attend $(n=10)$, followed up by health visitors only $(n=9)$, and attended clinic once and lost to follow up thereafter $(n=13)$.

Of the 184 children seen, 35 (19\%) were found to have heights $>-2 S D$ scores when measured by the auxologist. Data from the remaining $149(81 \%)$ were available for analysis. Of these, $69(46 \cdot 3 \%)$ were already under the care of a paediatrician. The outcome in these 149 children is shown in table 4 .

Of the 80 children not previously seen by a paediatrician 28 were seen by an experienced auxologist, found to have an annual velocity greater than the 25th centile, and therefore discharged without any further investigation except for a bone age on all the children and a karyotype from the girls where possible (all were normal). Thirty nine were referred to the

Table 4 Outcome of 149 children with heights $\leqslant-2 S D$ scores

\begin{tabular}{|c|c|c|c|}
\hline & $\begin{array}{l}\text { Already } \\
\text { seeing } \\
\text { paediatrician }\end{array}$ & $\begin{array}{l}\text { Newly } \\
\text { identified } \\
\text { by screening }\end{array}$ & Total \\
\hline \multirow{6}{*}{$\begin{array}{l}\text { Familial short stature } \\
\text { Constitutional delay } \\
\text { Combination } \\
\text { Short normal } \\
\text { Congenital abnormalities/ } \\
\text { syndromes, etc } \\
\text { Intrauterine growth }\end{array}$} & 14 & 11 & \\
\hline & & 23 & 55 \\
\hline & & 7 & \\
\hline & 0 & 16 & 16 \\
\hline & 25 & 2 & 27 \\
\hline & & & \\
\hline retardation & 8 & 3 & 11 \\
\hline Down's syndrome & 9 & 0 & 9 \\
\hline Cardiac defect & 6 & 0 & 6 \\
\hline Noonan's syndrome & 2 & 2 & 4 \\
\hline Bony dysplasia & 2 & 1 & 3 \\
\hline Turner's syndrome & 2 & 0 & 2 \\
\hline \multirow{3}{*}{$\begin{array}{l}\text { Growth hormone } \\
\text { deficiency } \\
\text { Emotional deprivation }\end{array}$} & & & \\
\hline & 1 & 1 & 2 \\
\hline & 0 & $i$ & 1 \\
\hline Total & 69 & 67 & $136^{\star}$ \\
\hline
\end{tabular}

*Thirteen still to evaluate. paediatric endocrinologist and 13 are still under evaluation.

Of the 69 who were already seeing a paediatrician, 21 were already seeing the paediatric endocrinologist. Twelve of these had pathological reasons for their short stature, three had had intrauterine growth retardation, and six had familial short stature.

The new pathology identified as a result of the screening was: one child with growth hormone insufficiency, two children with Noonan's syndrome, one child with emotional deprivation, one with pseudohypoparathyroidism, one with hypomelanosis of Ito, and one probable bony dysplasia.

\section{Discussion}

Growth screening may be an appropriate way of monitoring the health of the community and for the early identification of treatable causes of short stature. The Hall report recommended that all children should be routinely measured at 3 and 4.5 years, ${ }^{6}$ but if this recommendation is to be adopted, a simple cost effective method of screening the height of the total population of children has to be devised. We have attempted to achieve this goal by incorporating growth screening into the existing framework of the child health surveillance programme.

If we were to estimate the cost of carrying out the primary growth screening on a service basis then the cost of the screening programme can be broken down into a series of different elements. The first of these is health visiting times. If we assume that it takes three minutes per measurement (including recording time) then a total of 1000 hours of health visitor time has been used in the study so far. This equates to approximately $£ 9000$. The Minimetres used cost $£ 19$ each and were supplied to 130 health visitors at a cost of $£ 2470$. These costs leave out that of data entry. The study did involve a significant extra task for health visitors in the district not only because of the introduction of height measurements as a standard part of the developmental checks but also because the additional clerical tasks involved in filling in forms, and ensuring that the details were correct. The backlog of data entry on to the computer was simply due to lack of data entry personnel and it is predicted that when this moves from a 'research based' function to a 'service based' function it will no longer be a problem.

At present the majority of child health surveillance in this age group is carried out by either health visitors, clinical medical officers, or GPs. In our previous study we have shown that health visitors' measurements, although not ideal, are reasonably accurate for the assessment of short stature. ${ }^{9}$ With the provision of appropriate equipment, training, and a central reporting facility, growth screening can be accomplished by health visitors and community doctors as part of their checks on preschool children.

Despite having received training in using the Microtoises, some of the health visitors used either the Oxford wall chart or a tape measure. 
This may have introduced greater inaccuracy. The wall chart was used in $9.6 \%$ of the 3 year olds and $4.3 \%$ of the 4.5 year olds (the accuracy of this device was discussed in our earlier paper $\left.{ }^{9}\right)$. The tape measure was used to measure $23 \%$ of the 3 year olds and $5 \%$ of the 4.5 year olds. The accuracy of this method has not been assessed, and with the advent of the Minimetre this is the recommended piece of equipment for routine screening of height in children.

Throughout the district about $90 \%$ of health visitors have cooperated with the studies as have fundholding and non-fundholding GPs. Some health visitors reported practical difficulties in obtaining measurements particularly in 3 year olds. Further administrative problems have arisen due to late returns and a backlog of data entry suggesting areas for improvements in overall coverage. Overall, however, ascertainment in our preliminary studies has been between 70 and $80 \%$.

The frequency distribution of height SD scores for the 20338 children shows a shift to the right, especially at the younger ages. The sample size means it is unlikely that this change is due to chance. The shift in height SD scores reflects the secular trend in growth but it is greater than that described by Chinn et al ${ }^{15}$ and Voss et $a l^{7}$ but similar to that reported in a recent London study of 7 year olds. ${ }^{16}$ It is possible that there was selection bias in that the Oxfordshire sample could be of a higher socioeconomic status than the samples reported in those other studies. ${ }^{715}$ The change in height SD score calculated from measurements obtained at the age of 3 and 4.5 years in both sexes was unexpected (table 2). The difference was most marked in males, the mean height SD score was 0.33 at 3 years and 0.20 at 4.5 years. Curiously the discrepancy was less marked in the cohort of children measured at both ages. It is possible that it reflects problems with the measurement of the younger children and we have noted in our previous study a tendency to report the 3 year olds as being 'greater' than expected. ${ }^{9}$ Alternatively the difference may highlight secular changes in the pattern of growth over this age range or reflect problems in the construction of the original Tanner and Whitehouse growth charts.

Our growth screening programme was designed to allow early identification of treatable causes of short stature. Of 260 children reported to be $\leqslant-2 S D$ scores, 35 were found to be $>-2 S D$ scores when they were measured by an experienced auxologist. The false negative rate is of course unknown but should be minimised by the second screening. In those children whose heights were definitely $\leqslant-2 S D$ scores, 69 were already under the care of paediatricians, but not always for the reasons of short stature: of these 21 were already seeing the paediatric endocrinologist and the remainder a variety of paediatric medical and surgical specialists. Altogether 149 short children were detected who required follow up and investigation. Screening of these children in the community growth assessment clinics was particularly useful as false positives were rapidly eliminated and referral to the endocrine clinic was limited. Many families once reassured that short stature was due to familial or constitutional delay, did not want further follow up.

To date only $21 \%$ of the short stature identified by screening was attributable to organic disease. This compares with $17 \%$ in the Wessex study ${ }^{17}$ and $18 \%$ in the Newcastle upon Tyne study. ${ }^{5}$ Of the specific diagnoses causing short stature the most important are growth hormone deficiency, Turner's syndrome, thyroid deficiency, and emotional deprivation. In our study two children out of 20000 screened were found to be growth hormone deficient, compared with a reported incidence of one per 3000-4000; two cases of Turner's syndrome were found compared with a reported incidence of one per 2500-3000. Thyroid deficiency is rarely found in this age group now that congenital cases are excluded. The incidence of emotional deprivation is unknown.

The reasons for the low incidence of growth hormone deficiency and Turner's syndrome is still to be determined. Only $75 \%$ of the population were screened and there may be undiscovered cases in those who were not screened. There may be further children with Turner's syndrome and growth hormone deficiency who are as yet undiagnosed among those children still being followed up in the community clinics. The more intriguing possibility is that some of the children with these conditions may still be within the normal height centiles yet they are growing slowly. Examination of growth charts specific for Turner's syndrome ${ }^{18}$ indicates that 40 to $50 \%$ of such girls are above the third centile at 3 and 4.5 years. This may also be true for a smaller proportion of growth hormone deficient children who were of normal size at birth. If we are to detect these children at 3 and 4.5 years screening must also encompass an estimate of growth velocity. Our height velocity data are similar to those reported by Tanner and Whitehouse in 1966 and are in contrast to reports from Southampton that height velocity has increased. ${ }^{7}$ This requires clarification as measurement errors are unlikely to explain the discrepancy in the mean velocity and mean velocity SD scores when the sample size is so large. The SD of the velocity SD score, however, was larger than expected and included 'blips' at each end of the distribution that can be attributed to measurement error. As we have argued before, health visitor measurements may not be suitable for velocity assessment. ${ }^{9}$ Sorva et al have devised standards using changes in height SD scores as indirect measurements of growth velocity, ${ }^{19}$ but these require further study.

In conclusion, with all its limitations we have described a model for a relatively cheap and realistic programme of height screening and follow up of short children. The advantages of such a programme are that it keeps the majority of children who are short for nonpathological reasons away from expensive hospital facilities. 
We would like to thank Eli Lilly for their financial support, Alan Vickers for writing the software programmes, Fiona Duncan for typing the manuscript, and John Shaw for help in data analysis. We also thank all the health visitors and GPs in the Oxfordshire district for their endless help and the community health personnel and Clare, Emma, Kirstin, and Sophie for their work in the community health offices.

1 Jordan J, Ruben M, Hernandez J, Bebelagua A, Tanner JM Goldstein H. The 1972 Cuban National Child Growth Study as an example of population health monitoring: Study as an example of population health monito
design and methods. Ann Hum Biol 1975; 2: 153-71.

2 Van Wieringen JC, Wafelbakker F, Berbrugge HP, de Haas Van Wieringen JC, Wafelbakker F, Berbrugge HP, de Haas JH. Growth diagrams 1975. Leiden:

3 Hamill PVV, Drizd TA, Johnson CL, Reed RB, Roche AF, Moore WM. Physical growth: National Center for Health Statistics percentiles. Am $\mathcal{f}$ Clin Nutr 1979; 32: 607-29.

4 Rona RJ, Altman GA. National Study of Health and Growth: Standards of attained height, weight and triceps skinfold in English children 5 to 11 years old. Ann Hum Biol 1977; 4: 501-23.

5 Lacey KA, Parkin JM. The causes of short stature: a community study of children in Newcastle upon Tyne. Lancet 1974; i: 42-5.

6 Hall D, ed. Health for all children. Oxford: Oxford Medical Publications, 1991.

7 Voss L, Walker J, Lunt H, Wilkin T, Betts P. The Wessex growth study: first report. Acta Paediatr Scand (Suppl) 1989; 349: 65-72.

8 Aynsley-Green A, Macfarlane JA. Method for the earlier recognition of abnormal stature. Arch Dis Child 1983; 58: 535-7.
9 Ahmed ML, Yudkin PL, Macfarlane JA, McPherson K, Dunger DB. Are measurements of height made by health visitors sufficiently accurate for routine screening of growth? Arch Dis Child 1990; 65: 1345-8.

10 Tanner JM, Whitehouse RH, Takaishi M. Standards from birth to maturity for height, weight, height velocity, and weight velocity: British children 1965. Part I. Arch Dis Child 1966; 41: 454-71.

11 Tanner JM, Whitehouse RH, Takaishi $M$. Standards from birth to maturity for height, weight, height velocity, and weight velocity: British children 1965. Part II. Arch Dis Child 1966; 41: 613-35.

12 Cameron N. The measurement of human growth. London: Croom Helm, 1984.

13 Tanner JM, Whitehouse RH, Cameron N, Marshall WA Healy MJR, Goldstein H. Assessment of skeletal maturity and prediction of adult height (TW2 method). London: Academic Press, 1983

14 Office of Population Censuses and Surveys. Vital statistics, local and health authority areas. Series VS Nos 10-14. London: HMSO, 1985-9.

15 Chinn S, Price CE, Rona RJ. Need for new reference curves for height. Arch Dis Child 1989; 64: 1545-53.

16 Elliman A, Bryan E, Elliman A, Walker J, Harvey D. The growth of low-birth-weight children. Acta Paediatr 1992; 81: $311-4$.

17 Voss LD. Tests for growth hormone secretion (letter). Arch Dis Child 1991; 66: 1465 .

18 Lyon AJ, Preece MA, Grant DB. Growth curve for girls with Turner's syndrome. Arch Dis Child 1985; 60: 932-5.

19 Sorva R, Lankinen S, Tolppanen EM, Perheentupa J Variation of growth in height and weight of children. II: after infancy. Acta Paediatr Scand 1990; 79; 498-506. 